\title{
Electrochemical Detection of Daphnetin Based on a Glassy Carbon Electrode Modified with Nafion and RGO-TEPA
}

\author{
Ming Zhou, Yunjie Sheng, Yangchun Li, Yurong Wang* \\ College of Pharmaceutical Science, Zhejiang Chinese Medical University, Hangzhou 310053, China \\ *E-mail: wangyr@zcmu.edu.cn
}

doi: $10.20964 / 2021.04 .46$

Received: 2 December 2020 / Accepted: 25 January 2021 / Published: 28 February 2021

\begin{abstract}
A sensitive electrochemical sensor composed of Nafion, tetraethylene pentamine-functionalized reduced graphene oxide (RGO-TEPA), and a glassy carbon electrode (GCE) was developed to analyze daphnetin (DAPH). The electrochemical behavior of DAPH on Nafion/RGO-TEPA/GCE was studied by cyclic voltammetry. The electroanalytical method for DAPH detection was established using differential pulse voltammetry. A detection limit of $0.5 \mathrm{nM}(S / N=3)$ and a linear calibration range of 0.1 to $10 \mu \mathrm{M}$ were obtained. The reproducibility and repeatability of the method were calculated to be $1.6 \%$ and $4.8 \%$, respectively. The sensor showed good selectivity for DAPH and was successfully applied to detect DAPH in Zushima tablets. The content of DAPH in Zushima tablets detected by our sensor agreed well with that detected by HPLC.
\end{abstract}

Keywords: Daphnetin; electrochemical sensor; Nafion; reduced graphene oxide-tetraethylene pentamine (RGO-TEPA)

\section{$\underline{\text { FULL TEXT }}$}

(C) 2021 The Authors. Published by ESG (www.electrochemsci.org). This article is an open access article distributed under the terms and conditions of the Creative Commons Attribution license (http://creativecommons.org/licenses/by/4.0/). 